\title{
A qualitative analysis of student experiences of a blended learning course
}

\section{Peter A. M. Ruijten, Eline J. M. Hooijman}

Department of Industrial Engineering \& Innovation Sciences, Eindhoven University of Technology, The Netherlands.

\begin{abstract}
Blended learning has become a popular topic in higher education. A blended learning course combines face-to-face instructions with computer-mediated instructions in any possible ratio. Even though studies have investigated effects of blended learning on education costs and student performance, not much is known about how students experience a blended learning course. The current study provides insights into student experiences in a blended learning course in which all materials were available online, and a minimum number of faceto-face meetings was organized. Three students of the course participated in an in-depth interview, and all fourteen students of the course provided answers to questions during four face-to-face tutorials. Findings indicate similarities in their needs, but differences in their perception of the flexibility that was given to them in the course. A possible explanation for the differences in perception of flexibility could be the students' self-efficacy. Future studies should be designed to investigate which factors contribute to a positive student experience of blended learning.
\end{abstract}

Keywords: Blended learning; Student experiences; Interviews; Flexibility; Self-efficacy. 


\section{Introduction}

In 2003, blended learning emerged in the industry of knowledge delivery (Rooney, 2003). The rapid growth of digital technology (Bonk \& Graham, 2006) as well as the need for more cost-effective and efficient learning environments (Selim, 2007) quickly increased the popularity of blended learning. Bonk and Graham (2006) describe blended learning as a system in which face-to-face instruction is combined with computer-mediated instruction. Face-to-face learning is considered as traditional learning, involving interactions between a teacher and students in a live physical synchronous environment. In contrast, computermediated learning is based on a distributed learning system, emphasizing self-paced learning in an asynchronous, low fidelity environment (Bonk \& Graham, 2006).

Dean, Stahl, Sylwester and Peat (2001) explored the effectiveness of a specific distance education program for physicians at the University of Tennessee. This program was considered a blended learning program since it used a mixed-mode delivery of information. The program was completed in half of the time at less than half of the costs than a traditional program, and it contributed to positive learning outcomes (Dean et al., 2001). A metaanalysis regarding the effectiveness of online and blended learning showed a significant increase in performance with blended learning compared to face-to-face learning (Means, Toyama, Murphy, and Baki, 2013). These findings should however be interpreted with caution, because blended learning tends to be paired with additional learning time, instructional resources, and encouragement of interaction among learners, which was not controlled for in the study (Means et al., 2013).

While the benefits in terms of cost-effectiveness and student performance are promising, it is equally important to also optimize student satisfaction with blended learning. Some studies investigated students' acceptance of blended learning (e.g., Yeou, 2016) or their satisfaction with it (e.g., Bentley, Selassie, \& Parkin, 2012). Other studies investigated students' opinions about blended learning courses (Pfennig, 2017) and engagement in terms of participation (Kritzinger, Lemmens, \& Potgieter, 2018). Not much is known however about how students experience blended learning courses.

To fill this gap, a study was designed to investigate student experiences with a blended learning course, and define crucial success factors and barriers of blended learning from a student perspective. The framework that was used to investigate student experiences was the Technology Acceptance Model (TAM) as introduced by Davis (1989). This model describes fundamental factors that determine acceptance of technology, and can easily be adapted to fit the context of a blended learning course. Following this model, students of a blended learning course were interviewed with the goal to gain insights in perceived usefulness, perceived ease of use, attitude, intention to use, and actual use of the blended learning course. 


\section{Method}

\subsection{Participants and Design}

Three students following the blended learning course Behavioral Research Methods I during educational year 2017-2018 (PP 1-3) were asked to participate in an in-depth interview concerning their experiences with the blended learning course. All three of them were female, with an age ranging from 21 to 30 years $(M=24.7, S D=4.73)$. In addition, all fourteen students of the course were asked during each of four face-to-face tutorials to fill in a socalled one-minute paper: a sheet with three questions concerning their current thoughts about the blended learning course.

\subsection{Materials and Procedure}

Semi-structured interviews were performed by a researcher other than the teacher of the course, via Skype. In the interviews, students answered questions about their experiences with the blended learning course they were following at that time. The interview questions were largely based on TAM (Davis, 1989), were modified to open questions, and adapted to the blended learning course. Questions reflected the perceived usefulness of a blended learning course, the perceived ease of use of the Learning Management System (LMS) that was used for the course, the attitude students had towards the course, the intention to participate in other blended learning courses, and which factors are important to make a blended learning course successful.

\subsection{Data analysis}

The interviews were transcribed instantly and analyzed following the guidelines of thematic analysis (Braun \& Clarke, 2006). This analysis was iterative, in which the data was reviewed multiple times, and themes were checked against the collected data in both the interviews and the one-minute papers.

\section{Results}

The transcribed interviews were summarized and coded, and codes were categorized into five themes: easy information access, need for face-to-face interaction, need for clear expectation management, flexibility as a liability, and flexibility as an asset. Interestingly, students mostly agreed about the needs they had regarding blended learning, but they differed in their experiences regarding the flexibility of the course. All themes and subthemes are visualized in Figure 1, and they are discussed in detail in the subsections below. The last part of this section explores whether differences in students' performance occurred between the course as a traditional classroom course and a blended course. 


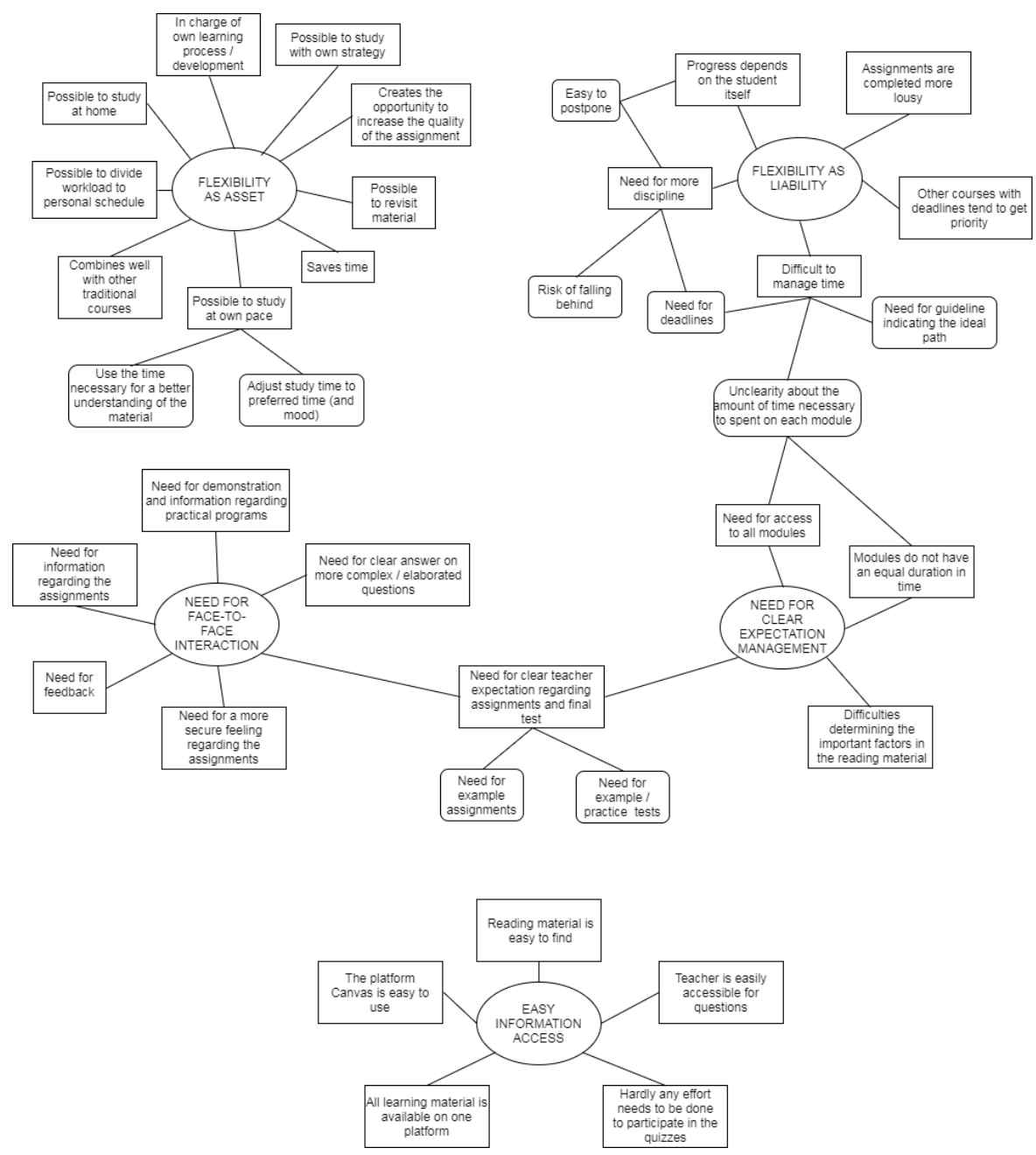

Figure 1. Overview of the relationship between themes and subthemes found in the interviews.

\subsection{Easy information access}

Students indicated that it was easy to find and retrieve information from the LMS. Having all information on one platform was considered to contribute to the ease of use of the blended learning course. In contrast to traditional courses in which learning material is usually provided through multiple different means, information being presented on one platform was considered as more efficient. One student stated: 'You will get [to the quiz] automatically, there is nothing you have to do. You just click "next" and you will get the next question' [PP1], showing that having a sequential order of information and tasks on the platform is experienced as an asset of blended learning. 


\subsection{Need for face-to-face interaction}

Despite the positive experiences with the LMS guiding students through the course, students still indicate a need for face-to-face interaction. According to the students, this face-to-face interaction would make them more informed and secure about the assignments in the course. Students also indicated that having the opportunity to have face-to-face interactions with the teacher motivates them. As one student put it: '[I would like to have] one-to-one interaction with the teacher really in front of you. That works so much better for me. Then I get more motivated externally' [PP3].

Another reason for having face-to-face meetings is that students struggled with their understanding of how the statistical analysis program worked. A need for demonstrations was mentioned multiple times in the interviews. Of course, these demonstrations could be provided through other means than face-to-face interactions.

\subsection{Need for clear expectation management}

One aspect that was mentioned by all three students in the interviews was that they would like to have more information regarding the time necessary for the separate elements of the course. When students are responsible for planning activities in the course independently, they would benefit from information regarding the expected duration of each task. One of the students explained the struggle she had with planning and how that led to motivational difficulties: 'At the beginning [of the course] I knew that there were ten modules, so I planned to make one every week. However, the size of the modules differed so much. Assignment 1 was only an hour and another [assignment] five hours. So I put the rest [of the course] on a low level' [PP3].

In addition to problems with time management, students also mentioned a lack of clarity about the expected quality of their assignments. They did not see opportunities for discussing this issue with the teacher of the course. One student indicated this by stating: 'Regarding the assignments, it was sometimes difficult to know what was asked from us. Maybe that giving examples is a good idea, so that we can see something of what is expected from you, instead of figuring it out yourself' [PP2]. The question remains what the best way is to assist students with this if there is no face-to-face contact.

\subsection{Flexibility as a liability}

Organizing a blended learning course allows students to study at their own pace, but a problem that was mentioned about this flexibility was that students experienced a lack of external pressure for finishing assignments. This could lead to procrastination, as one student mentioned: 'You really need to have discipline to do it. So if you do not feel like it, it becomes very easy to do nothing. That is one of the risks of blended learning' [PP2]. Due to the lack 
of external pressure in the blended learning course, other courses which do comply with this external pressure and have deadlines, tend to be prioritized over the blended learning course.

There were no deadlines in the blended learning course other than finishing all the work before the exam period, resulting in difficulties related to time management. Students indicated a need for stricter deadlines or guidelines that provides students with an example planning. One student proposed the following solution: 'What I would like more is that I can see what part of the work I already completed. A kind of loading bar per module, that you will see "hey, you have $80 \%$ of the work completed", or something' [PP1].

\subsection{Flexibility as an asset}

Interestingly, flexibility was also seen as an asset. Students appreciated the possibility to work on the course in their own pace, and that they could decide when to work on the course (rather than having fixed lecture hours). One of the students stated that: 'It gives me the opportunity to plan for myself when I do something [for the course]. Because I plan for myself, I know when I have time to do something. So now I can focus whenever I have motivation. When someone obliges me to focus, then it will not work' [PP2].

Additionally, students mentioned that studying at their own pace created an opportunity to use the time necessary to understand the learning material better. As one student put it: 'If you get explanation [of the learning material] you will absorb [the material] less well than going through [the material] yourself' [PP2]. The flexibility thus allowed students to be more in charge of their own learning process, which was experienced very positively.

An important insight is that a blended learning course can be combined well with traditional courses: 'We have two other courses. I liked it that one of them was a blended learning course' [PP1]. This shows that blended learning courses can be used in educational programs, as long as there are still traditional classroom courses as well.

\subsection{Student performance}

In addition to student experiences, we analyzed whether there was a difference in student performance between the blended learning course and the same course given to 10 students in a traditional classroom setting in 2016-2017. No significant difference in final grade of the course was found between year 2016-2017 $(M=6.42, S D=1.72)$ and year 2017-2018 $(M=$ $6.91, S D=0.82), t(22)=0.94, p=0.36$. This result shows that changing the course into a blended learning course did not significantly influence overall student performance.

\section{Discussion}

A study was performed to investigate students' experiences of a blended learning course.

Three students of the course were interviewed, and all fourteen students filled in one-minute 
papers throughout the course. A thematic analysis revealed five main themes. Students had similar needs regarding face-to-face interactions and knowing what was expected from them in the course, and the current set-up did not fulfill those needs. Earlier work also showed that students do not believe that online tutorials could or should replace face-to-face tutorials (Sweeney, O'donoghue, \& Whitehead, 2004), but students in the current study indicated that face-to-face interactions are mostly needed for grasping specific knowledge. Students in the current study were uncertain about the amount of time they had to spend on each module, leading to difficulties in their time management. Providing insights into the modules from the beginning of the course or providing a course planning to the students might give them a stronger feeling of control, and allows them to plan their activities more accurately.

Students differed in the extent to which they liked the flexibility in the course. Positive aspects of the flexibility that was offered were the possibility to study at their own pace, being in charge of one's own learning process, and the possibility to work on all aspects of the course from home. However, too much flexibility in the course has negative effects as well. Students experienced a lack of external pressure, found it difficult to allocate time to the course, and partly lost their motivation to study. This shows the importance of proper communication about what is expected from students, but also may indicate that different students need a different approach.

Research in the learning domain indicates that differences in student learning and academic achievement might be explained by self-efficacy. Students with a higher level of perceived self-efficacy set both higher and more productive mastery goals (Walker \& Greene, 2009), and choose to engage in tasks which are more challenging (Bandura, 1993; Bandura \& Schunk, 1981). This may make those students more likely to thrive from flexibility, whereas students low in self-efficacy may perceive flexibility as a liability. The current study did not measure self-efficacy, so there is no way of knowing whether this explains the current findings. Future work should therefore be designed to investigate the relationship between self-efficacy and students' perception of flexibility in blended learning courses.

When comparing the average course grades of the same course in a traditional classroom setting with a blended learning version, no statistical differences were found in student performance. However, the average grade of students in the bleded learning course was almost half a point higher. In order to find out whether students in a blended learning course indeed significantly outperform students in a traditional course, further research should be conducted in which performance in students is examined with larger samples. 


\section{References}

Bandura, A. (1993). Perceived self-efficacy in cognitive development and functioning. Educational Psychologist, 28(2), 117-148. doi: 10.1207/s15326985ep2802_3.

Bandura, A., \& Schunk, D. H. (1981). Cultivating competence, self-efficacy, and intrinsic interest through proximal self-motivation. Journal of personality and social psychology, 41(3), 586. doi: 10.1037/0022-3514.41.3.586.

Bentley, Y., Selassie, H., \& Parkin, E. (2012). Evaluation of a global blended learning MBA programme. The International Journal of Management Education, 10(2), 75-87. doi: 10.1016/j.ijme.2012.03.001.

Bonk, C. J., \& Graham, C. R. (2006). The Handbook of Blended Learning. San Francisco: Pfeiffer.

Braun, V., \& Clarke, V. (2006). Using thematic analysis in psychology. Qualitative Research in Psychology, 3(2), 77-101. doi:10.1191/1478088706qp063oa.

Davis, F. D. (1989). Perceived usefulness, perceived ease of use and user acceptance of information technology. MIS Quarterly, 23(2), 145-158. doi: 10.2307/249008.

Dean, P. J., Stahl, M. J., Sylwester, D. L., \& Peat, J. A. (2001). Effectiveness of combined delivery modalities for distance learning and resident learning. Distance Education, 2(3), 247-254.

Kritzinger, A., Lemmens, J., \& Potgieter, M. (2018, July). Improving the quality of learning in a blended learning environment for first-year biology. 4th International Conference on Higher Education Advances (HEAd'18), 159-166. doi: 10.4995/HEAD18.2018.7917.

Means, B., Toyama, Y., Murphy, R., \& Baki, M. (2013). The effectiveness of online and blended learning: A meta-analysis of the emperical literature. Teachers College Record, $115(1), 47$.

Pfennig, A. (2017). Improvement of learning outcome in material science through inverted classroom techniques and alternative course assessment. 3rd International Conference on Higher Education Advances (HEAd'17), 159-166. doi: 10.4995/HEAd17.2017.4936.

Rooney, J.E. (2003). Blending learning opportunities to enhance educational programming and meetings. Association Management, 55(5), 26-32.

Selim, H. M. (2007). Critical success factors for e-learning acceptance: Confirmatory factor models. Computers \& Education, 49(2), 396-413. doi: 10.1016/j.compedu.2005.09.004.

Sweeney, J., O'donoghue, T., \& Whitehead, C. (2004). Traditional face-to-face and webbased tutorials: a study of university students' perspectives on the roles of tutorial participants. Teaching in higher education, 9(3), 311-323. doi:10.1080/1356251042000216633.

Walker, C. O., \& Greene, B. A. (2009). The relations between student motivational beliefs and cognitive engagement in high school. The Journal of Educational Research, 102(6), 463-472. doi: 10.3200/JOER.102.6.463-472.

Yeou, M. (2016). An investigation of students' acceptance of moodle in a blended learning setting using technology acceptance model. Journal of Educational Technology Systems, 44(3), 300-318. doi: 10.1177/0047239515618464. 